\title{
Tensile and Flexural Properties of Chopped Strand E-glass Fibre Mat Reinforced CNSL- Epoxy Composites.
}

\author{
Suhas Yeshwant Nayak ${ }^{1}$, Srinivas Shenoy Heckadka ${ }^{1 *}$, Linto George Thomas ${ }^{1}$, and Anil \\ $B a b y^{1}$ \\ ${ }^{1}$ Department of Mechanical and Manufacturing Engineering, Manipal Institute of Technology, \\ Manipal Academy of Higher Education, Manipal, India
}

\begin{abstract}
Glass fibres have the principal advantages such as high tensile strength, high chemical resistance, low cost, and excellent insulating properties which makes them an important constituent in fibre reinforced plastic and composite industry. In this study, E-glass fibre in the form of Chopped Strand Mat (CSM) with different weight fractions such as $15 \%$, $30 \%$, and $45 \%$ were used as reinforcement in CNSL-epoxy resin composites. Fabrication of the composites was done by hand layup technique. Micro-hardness, tensile and flexural properties were investigated for all the composite panels of different compositions. The results clearly indicated an improvement in micro hardness, tensile and flexural properties with the increase in fibre content.
\end{abstract}

Keywords: E-glass fibre, Cashew nut liquid shell resin, Hand layup, Tensile strength and Flexural strength

\section{Introduction}

Glass fibre composites are being used in manufacture of numerous parts/products such as automobile parts, construction equipment parts, sports goods like surfboard, tennis rackets, fishing rods, golf clubs, archery bows and many other household applications due to reasonably high specific strength, tensile strength and hardness. Also, glass fibres are less expensive; possess good resistance to chemical attacks and insulating properties [1-3]. Utilization of glass fibre with appropriate orientation and proportion can yield composites with strength which are equivalent to steel, superior to aluminum in stiffness and one fourth of the steel in terms of specific gravity [4]. Mechanical and tribological properties of the composites can be enhanced by the usage of randomly oriented chopped fibre, chopped strand mat and woven mats [5]. Tungjitpornkull et al. [6] carried out the study on chopped strand E-glass fibre reinforced wood/PVC composites. They observed that tensile, flexural moduli and impact strength increased with the increasing content of the glass fibre due to its high stiffness. Gupta and Siddhartha [7] did a comparative study between bi-directional and chopped e-glass fibre epoxy reinforced composite materials. Bi-directional e-glass fibres exhibited better flexural and tensile modulus, wear characteristics and impact

${ }^{*}$ Corresponding author: srinivas.shenoy.h@gmail.com 
properties due to improved interface strength and superior hardness when compared to randomly orient chopped fibre composites. Bhaskar and Kolla [8] evaluated the properties of composites made of chopped strand mat and woven roving E-glass fibre. The results showed that chopped strand mat composites have better mechanical properties than woven roving E-glass fibre composite. Khan et al. [9] investigated the mechanical and interfacial properties of jute and E-glass fibre reinforced composites. The studies revealed that E-glass fibre composites have twice the mechanical strength when compared to jute fibre reinforced composites.

Thermosetting polymers are an excellent substitute for most of the conventional materials. Epoxy resins are one of the extensively used thermosetting resins. It is mostly used in the form of coatings and structural adhesives for many engineering applications in addition to its usage as matrices for fibre reinforced composites due to its superior thermal and mechanical properties, excellent corrosion and chemical resistance [10]. Hameed et al. [11] conducted a study on the utilisation of the modified epoxy resin as matrix in glass fibre composites. The results indicated that the thermoplastic modification is an excellent way to enhance the mechanical, thermal and dynamic properties of composites. Composites fabricated using modified matrix indicated better storage modulus, increased glass transition temperature and enhanced thermal stability. Muhammad and Ahmad [12] examined the mechanical and thermal properties of glass fibre reinforced epoxy composite with matrix modification using liquid epoxidized natural rubber. Results indicated an increase in mechanical properties due to matrix modification.

Cashew nut shell liquid (CNSL) is a heavy liquid with a lingering scent, produced from the shell of Anacardium occidentale (cashew nut tree). The raw CNSL contains 5\% of cardonal, $18 \%$ cardol and $70 \%$ anacardic acid and remaining polymeric materials. This raw CNSL is processed by heating to get modified CNSL. Composition of modified CNSL is $10 \%$ cardol, $52 \%$ cardanol, $30 \%$ polymeric material $[13,14]$. Resins which are developed from cashew nut liquid are hydrophobic in nature, due to which they have better resistance over water, acids, and alkalis. These resins also possess superior properties against other synthetic or conventional resins such as better friction resistant properties, corrosion resistance, are an effective thermosetting binder, and provide protection against heat and fire. CNSL resin modified with formaldehyde has found applications as automotive diskbrake pads, preparation of medium density particulate board, and composite wood [15]. Kim [16] explored the potential of CNSL as a green adhesive. Cashew nut shell liquid formaldehyde resin (CF) and Polyvinyl acetate resin (PVAc) was used. Better bonding over commercially available tannin adhesive, reduced formaldehyde and VOC emissions were reported. Bisanda and Ansell [13] analysed the thermal properties of sisal reinforced cashew nut shell liquid composite. CNSL polymerised with formaldehyde and sodium hydroxide as a catalyst was used to produce resol type polymer matrix for the sisal fibres. Priya et al. [17] studied the tensile behavior and chemical resistance of chopped glass strand mat reinforced epoxy composites toughened with epoxy phenol CNSL. Authors observed improved tensile, interfacial bonding and chemical resistance over regular epoxy composites.

From the literature survey conducted it is evident that CNSL has a potential in modifying traditional thermoset resins to obtain improved mechanical, thermal and chemical properties. CNSL is readily available as a by-product during processing of cashew nuts and hence is less expensive. Use of CNSL as a resin either as a whole or as a part in some other resin will help in bringing down the fabrication cost. Thus, the present study aims at determining the micro hardness, tensile and flexural properties of chopped E-glass CSM reinforced CNSL-epoxy matrix for engineering applications. 


\section{Experimental details}

\subsection{Materials}

E-glass CSM with areal density of 290 gsm was used as the reinforcement. The fabric was purchased from S \& S Polymers, Bangalore, India. The matrix is a blend of CNSL and epoxy resins. CNSL resin was procured from Shivam Cashew Industry Ahmedabad, India, and an unmodified medium viscosity Epoxy Bisphenol-12 resin (LAPOX L-12) with curing hardener (K6) were supplied by Atul Private Limited, Bangalore, India. The physical properties of the resins are shown in Table 1.

Table 1. Physical properties of matrices $[18,19]$

\begin{tabular}{|c|c|c|c|}
\hline Properties & Resin-1 & Resin-2 & Hardener \\
\hline Trade Name & CNSL-resin & Epoxy-resin & K-6 \\
\hline Density & $0.970 \mathrm{~kg} / \mathrm{m}^{3}$ & $1162 \mathrm{~kg} / \mathrm{m}^{3}$ & $954 \mathrm{~kg} / \mathrm{m}^{3}$ \\
\hline
\end{tabular}

\subsection{Fabrication of composite}

Composites were prepared by hand layup technique. E-glass CSM was used in three different weight fractions viz. $15 \%, 30 \%$ and $45 \%$ with CNSL-epoxy polymer matrix. The matrix was prepared by blending epoxy with CNSL in the ratio of $85: 15$ by weight. The blend was continuously stirred at room temperature for $30 \mathrm{~min}$.

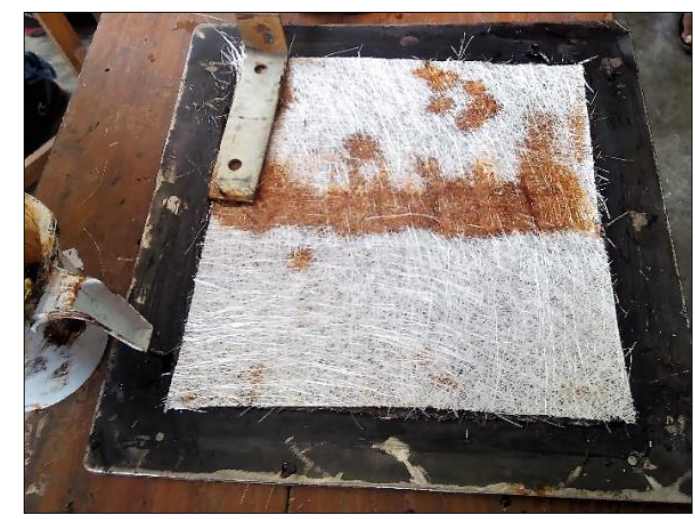

Fig. 1. Fabrication of composite laminates 
A closed mould of size $300 \mathrm{~mm}$ x $300 \mathrm{~mm}$ was used to fabricate the panels. To begin with a layer of CNSL-epoxy resin was uniformly spread over the gel coated mould surface. This was followed by laying up of alternate layers of CSM and resin mix. Peel ply film was placed on the outside to get a smooth surface finish. Fig. 1 shows the fabrication of composite panels with the first layer of reinforcement being laid. Total of 6 plies of CSM was used in the fabrication. The mould was closed and kept under a load of $6 \mathrm{~kg}$ for duration of $24 \mathrm{~h}$ at room temperature for curing. Post curing for 4 hours at $50^{\circ} \mathrm{c}$ was carried out in a hot air oven so that the crosslinking of the resin is complete. The thickness of the all cured laminates was $3 \pm 0.5 \mathrm{~mm}$. Test specimens were cut as per ASTM standards using water jet cutting at Om Waterjet Machine Pvt. Ltd, Bangalore, India. Table 2 presents the designation of composite laminates.

Table 2. Designation of composite laminates

\begin{tabular}{|c|c|}
\hline Composition & Designation \\
\hline CNSL-epoxy polymer resin & $\mathrm{C} 1$ \\
\hline $\begin{array}{c}15 \% \text { E-glass fibre }+85 \% \\
\text { CNSL-epoxy polymer resin }\end{array}$ & $\mathrm{C} 2$ \\
\hline $\begin{array}{c}30 \% \text { E-glass fibre }+70 \% \\
\text { CNSL-epoxy polymer resin }\end{array}$ & $\mathrm{C} 3$ \\
\hline $\begin{array}{c}45 \% \text { E-glass fibre }+55 \% \\
\text { CNSL-epoxy polymer resin }\end{array}$ & $\mathrm{C} 4$ \\
\hline
\end{tabular}

\subsection{Mechanical characterization of composites}

Micro hardness was determined by Matsuzawa micro-hardness tester (Model: MMT-X7A; Matsuzawa Co., Ltd. Japan). For each sample, six indentations were performed with an indentation load of $100 \mathrm{~g}$ and a dwell time of $15 \mathrm{~s}$ for indentation. A diamond indenter is forced into the material under a load $\mathrm{F}$, which leaves an indentation of square shape on the material surface. The lengths of the two diagonals $\mathrm{S}$ and $\mathrm{T}$ of the indentation are noted. The following equation calculates Vickers micro hardness.

$$
\begin{aligned}
& V_{h}=0.1889 \frac{F}{L^{2}} \\
& L=\frac{S+T}{2}
\end{aligned}
$$

where $\mathrm{L}$ is the mean diagonal of square impression $(\mathrm{mm}), \mathrm{F}$ is the applied load $(\mathrm{N}), \mathrm{S}(\mathrm{mm})$ and $T(\mathrm{~mm})$ are the horizontal and vertical diagonal length respectively. Tensile and flexural strength of the composite laminates were evaluated on a Zwick Roell universal testing machine. The samples for the tensile tests were cut to a dimension of $250 \mathrm{~mm} \times 25$ $\mathrm{mm}$ based on the ASTM D3039 [20] while the flexural samples were cut to an overall length of $120 \mathrm{~mm}$ with span length of $96 \mathrm{~mm}$ according to ASTM D7264 [21]. Cross head speeds were set at $2 \mathrm{~mm} / \mathrm{min}$ and $1 \mathrm{~mm} / \mathrm{min}$ for tensile and flexural tests respectively. Five specimens from each composition were tested for and the average values were reported. 


\section{Results and discussion}

The variation in average micro-hardness of E-glass fibre reinforced CNSL-epoxy composites with variation in the fibre weight fraction is presented in Fig. 2. Hardness improved with increase in fibre content, an increase of $68 \%$ in hardness was observed in $\mathrm{C} 4$ composites having fibre content of $45 \%$, when compared to neat polymer (C1). This is an indication of increased resistance to deformation and abrasion under indenter load. Reinforcements like glass fibres which are the discontinuous phase in any composite material are also the hardest phase unless it's a filled composite. Also, when tested for hardness, concentrated compressive loads are applied on the surface, which try to deform the material. These forces are resisted by the reinforcements thus increasing the hardness and results in minimum plastic deformation.

Fig. 3 presents the variation in the tensile strength of composites. It is evident that increase in fibre content improves the tensile strength of the composites. Highest tensile strength was obtained for composites with fibre content of $45 \%$ which is about 10 times more than the strength of neat polymers. For composites with fibre content of $15 \%$ and $30 \%$, the tensile strength obtained was $116 \mathrm{MPa}$ and $160 \mathrm{MPa}$ respectively. A huge improvement in tensile properties of the composites over neat polymers is mainly due to the load bearing capacity of E-glass fibres. Though E-glass fibres are known for its high strength and modulus, ineffective interfacial bonding between the various constituents would lead to unsound composites. Thus, it can be concluded that modification of epoxy with CNSL was successful.

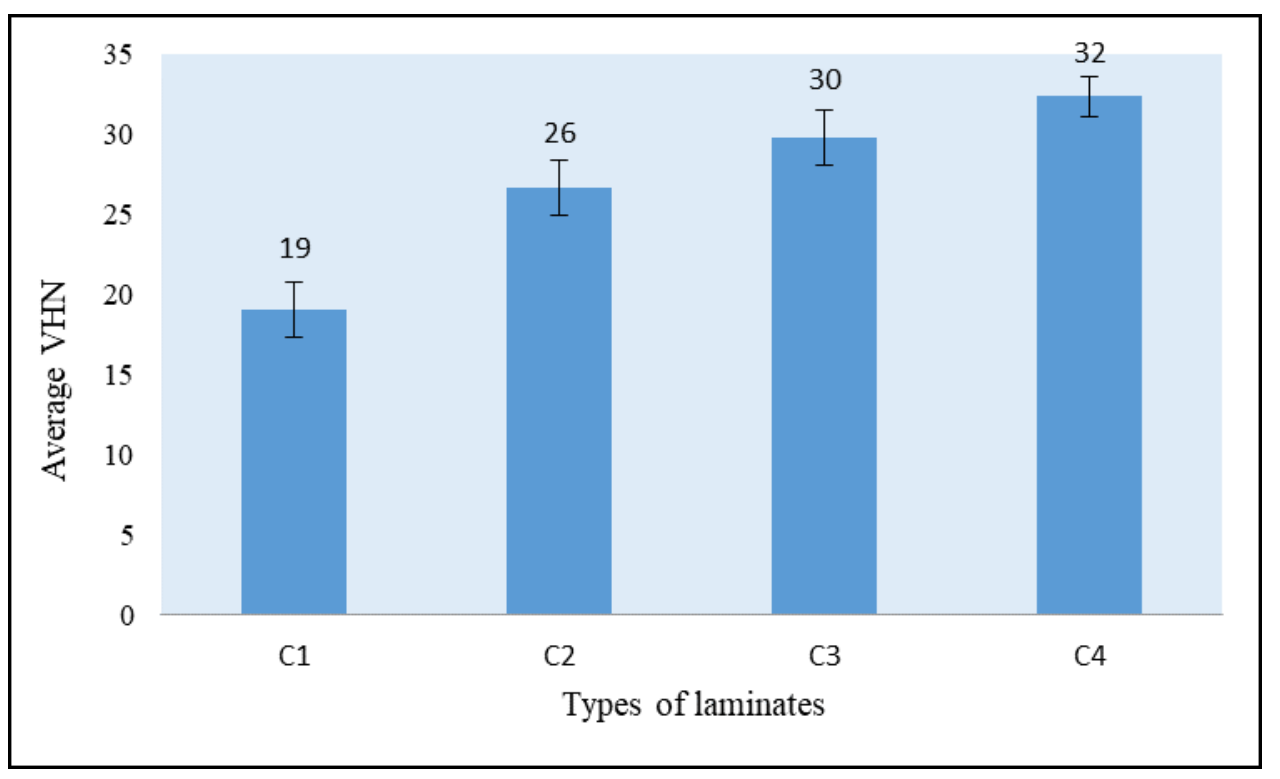

Fig. 2. Variation in average micro-hardness

Flexural strength (Fig. 4) of the chopped E-glass CSM reinforced CNSL-epoxy composite materials increased significantly with the fibre loading. This is an indication of good dispersion of fibres in the CNSL-epoxy matrix. The fibres in the mat are randomly oriented and are held together which increases it's through thickness strength thereby providing good resistance to bending forces. The maximum flexural strength of $166 \mathrm{MPa}$ was obtained for $\mathrm{C} 4$ composites with $45 \%$ fibre weight fraction. Similar observations were 
reported by researchers in the past $[7,12]$ wherein they established that increase in the fibre weight fraction induces an increase in flexural strength property of the epoxy composites.

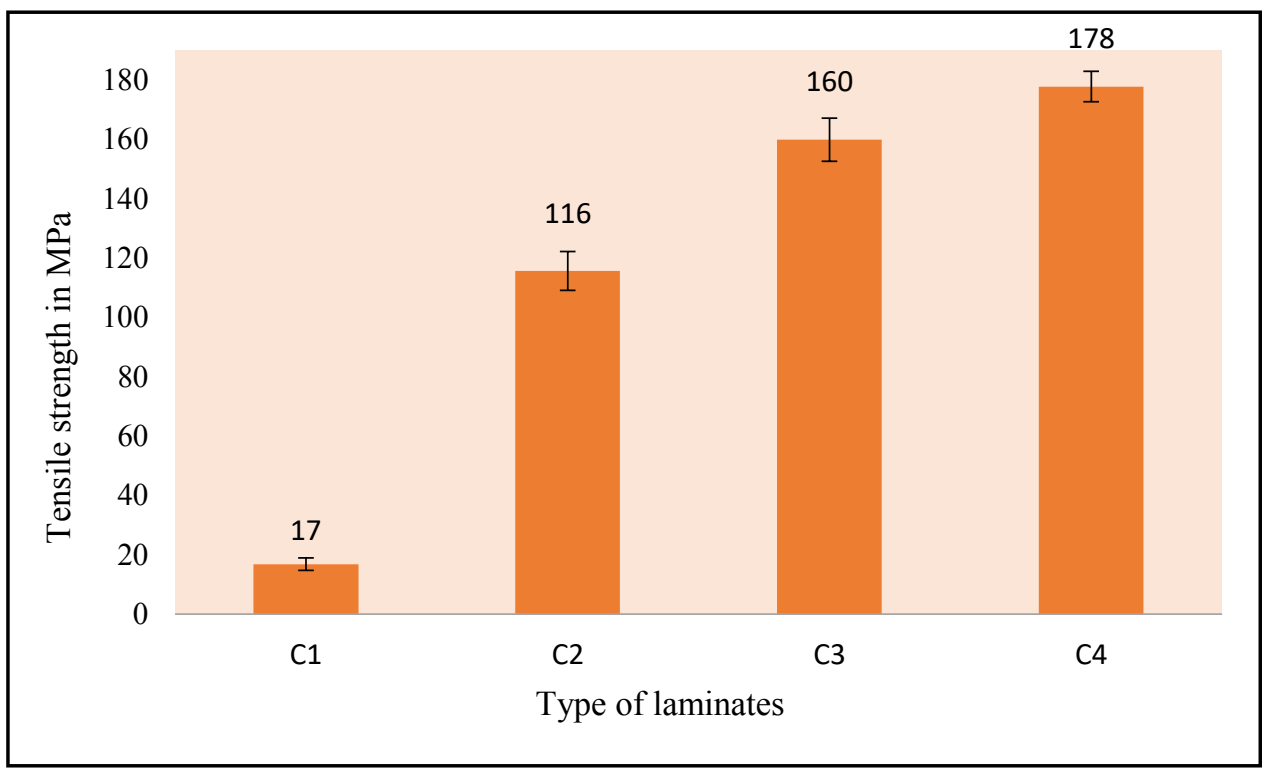

Fig. 3. Variation in average tensile strength

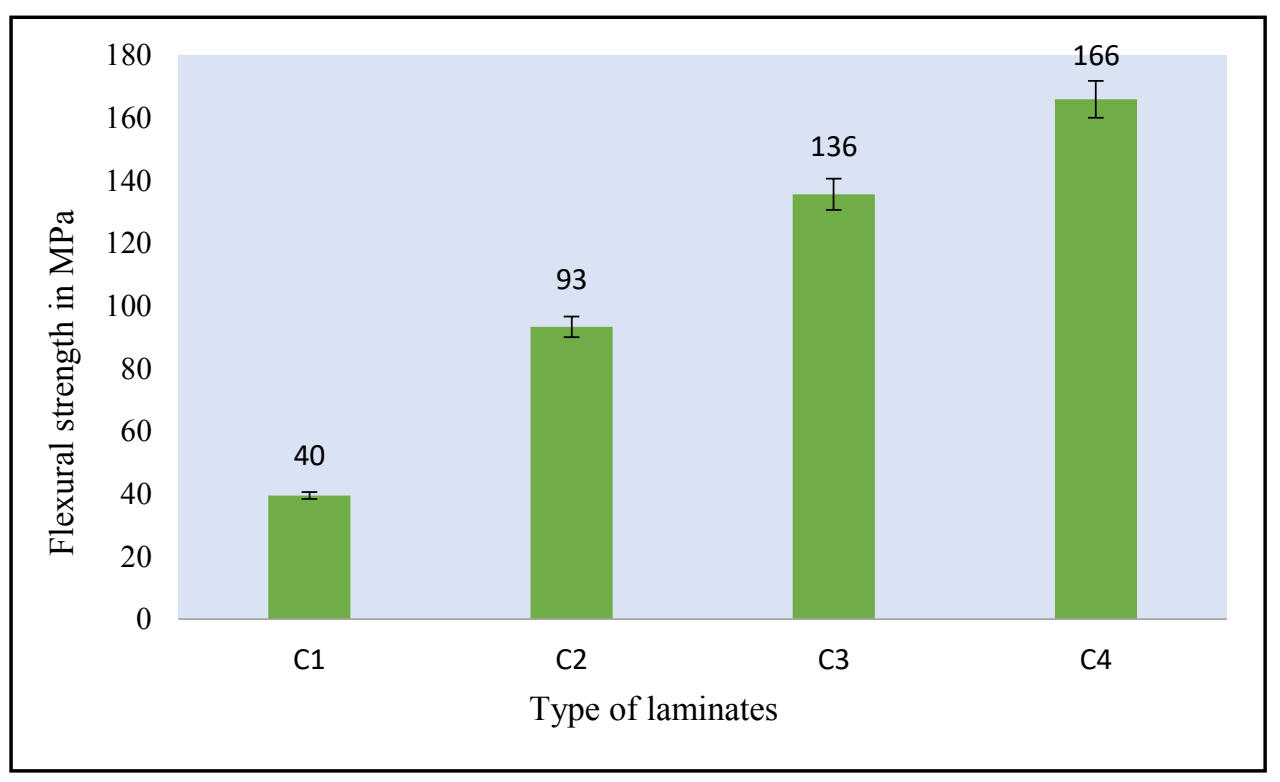

Fig. 4. Variation in average flexural strength

\section{Conclusions}

Composites fabricated with E-glass CSM in epoxy-CNSL resin showed improvement in micro hardness, tensile strength, and flexural strength over neat polymers. Identical trends 
were observed for all tests where increased fibre content resulted in improvement in properties. Improvement in properties is due to the inherent capability of the glass fibres to take up higher static loads before failure and also due to effective interfacial bonding between the constituents of the composites. This study shows that by adding CNSL to epoxy resin, mechanical properties of the composite laminates can be enhanced.

\section{Acknowledgment}

The authors are thankful to Dr. K. Jagannath, Head of the Department, Mechanical and Manufacturing Engineering for permitting us to make use of the Advanced Material Testing and Research Laboratory. The authors are also indebted to Dr. Satish Shenoy B, Professor and Head, and Dr. Dayanand Pai, Professor, Department of Aeronautical and Automobile Engineering for allowing us to use their Advanced Composite and Material Testing Laboratory. The authors would also like to thank M/s. Konkan Speciality Polyproducts Pvt. Ltd., Mangalore for providing us their testing facility.

\section{References}

1. Suresha, B., Chandramohan, G. and Renukappa, N. M., "Mechanical and tribological properties of glass-epoxy composites with and without graphite particulate filler". J APPL POLYM SCI, 103(4), pp.2472-2480. (2007)

2. Mallick, P. K., "Fiber-reinforced composites: materials, manufacturing, and design". CRC press. (2007)

3. Dadfar, M. R. and Ghadami, F., "Effect of rubber modification on fracture toughness properties of glass reinforced hot cured epoxy composites". Mater. Des, 47, pp.16-20. (2013)

4. Sathishkumar, T. P., Satheeshkumar, S. and Naveen, J., 2014. "Glass fiber-reinforced polymer composites-a review”. J REINF PLAST COMP, 33(13), pp.1258-1275.( 2013)

5. Nayak, S. Y., Heckadka, S. S., Sadanand, R. V., Bharadwaj, K., Pokharna, H. M. and Sanjeev, A. R.,"2D woven/3D orthogonal woven Non-crimp E-glass Fabric as Reinforcement in Epoxy Composites using Vacuum Assisted Resin Infusion Molding”. J ENG FIBER FABR, 12(2), pp.12-19.( 2017)

6. Tungjitpornkull, S., Chaochanchaikul, K. and Sombatsompop, N.,"Mechanical characterization of E-chopped strand glass fibre reinforced wood/PVC composites". J THERMOPLAST COMPOS, 20(6), pp.535-550.( 2007)

7. Gupta, K., and Siddhartha, "Mechanical and abrasive wear characterization of bidirectional and chopped E-glass fibre reinforced composite materials". Mater. Des, 35, pp.467-479.(2012)

8. Bhaskar, V. V. and Srinivas, K., "Mechanical characterization of glass fiber (woven roving/chopped strand mat E-glass fibre) reinforced polyester composites". AIP CONF PROC, 1859, No. 1, p. 020108. AIP Publishing.( 2017)

9. Khan, R. A., Khan, M. A., Zaman, H. U., Pervin, S., Khan, N., Sultana, S., Saha, M. and Mustafa, A. I., "Comparative studies of mechanical and interfacial properties between jute and E-glass fibre-reinforced polypropylene composites". J REINF PLAST COMP, 29(7), pp.1078-1088.(2010) 
10. Shivamurthy, B., Bhat, K. U. and Anandhan, S., "Mechanical and sliding wear properties of multi-layered laminates from glass fabric/graphite/epoxy composites". Mater. Des, 44, pp.136-143.( 2013)

11. Hameed, N., Sreekumar, P. A., Francis, B., Yang, W. and Thomas, S., "Morphology, dynamic mechanical and thermal studies on poly (styrene-co-acrylonitrile) modified epoxy resin/glass fibre composites". Compos Part A Appl Sci Manuf., 38(12), pp.2422-2432.(2007)

12. Muhammad, Y. H. and Ahmad, S., "Mechanical and thermal properties of glass fibrereinforced epoxy composite with matrix modification using liquid epoxidized natural rubber". J REINF PLAST COMP, 32(9), pp.612-618(2013)

13. Bisanda, E. T. N. and Ansell, M. P., "Properties of sisal-CNSL composites". J MATER SCI, 27(6), pp.1690-1700.(1992)

14. Akinhanmi, T. F., Atasie, V. N. and Akintokun, P. O. "Chemical composition and physicochemical properties of cashew nut (Anacardium occidentale) oil and cashew nut shell liquid". J AGR FOOD ENVIR SCI, 2(1), pp.1-10.(2008)

15. Telascrêa, M., Leão, A. L., Ferreira, M. Z., Pupo, H. F. D. F., Cherian, B. M. and Narine, S. "Use of a Cashew Nut Shell Liquid Resin as a Potential Replacement for Phenolic Resins in the Preparation of Panels-A Review". Mol. Cryst. Liq. Cryst., 604(1), pp.222-232. (2014)

16. Kim, S."The reduction of formaldehyde and VOCs emission from wood-based flooring by green adhesive using cashew nut shell liquid (CNSL)". J HAZARD MATER, 182(1), pp.919-922.(2010)

17. Priya, S. P., Ramakrishna, H. V., Rai, S. K. and Rajulu, A. V. "Studies on tensile properties and chemical resistance of glass mat-epoxy toughened with epoxy phenol CNSL composites". J REINF PLAST COMP, 25(2), pp.141-147.(2006)

18. Lubi, M. C. and Thachil, E. T. "Cashew nut shell liquid (CNSL)-a versatile monomer for polymer synthesis”. Des. Monomers Polym., 3(2), pp.123-153.(2000)

19. Heckadka, S. S., Nayak, S. Y., Narang, K. and Vardhan Pant, K. "Chopped Strand/Plain Weave E-Glass as Reinforcement in Vacuum Bagged Epoxy Composites". J MATER, 2015, (2015)

20. ASTM D3039 / D3039M-14, Standard Test Method for Tensile Properties of Polymer Matrix Composite Materials, ASTM International, West Conshohocken, PA, 2014, Www.astm.org

21. ASTM D7264 / D7264M-07, Standard Test Method for Flexural Properties of Polymer Matrix Composite Materials, ASTM International, West Conshohocken, PA, 2007, www.astm.org 